\title{
THE INFLUENCE OF ACTIVE REHABILITATION ON THE RECOVERY OF COGNITIVE AND PSYCHOEMOTIONAL DISORDERS AFTER ISCHEMIC STROKE
}

DOI: $10.36740 /$ WLek202108123

\author{
Oleksandr 0. Pushko \\ POLTAVA STATE MEDICAL UNIVERSITY, POLTAVA, UKRAINE
}

\begin{abstract}
The aim: Was to evaluate the impact of active rehabilitation treatment in the scheme of comprehensive therapy of patients with cerebral hemispheric ischemic stroke on the dynamics of recovery of cognitive and psychoemotional disorders, as well as to study their correlations.

Materials and methods: The study involved 138 patients: 30 apparently healthy individuals (control group, $\mathrm{CG}, \mathrm{n}=30$ ) without acute cerebrovascular disorders (anamnestic and neuroimaging), of whom $53.33 \%$ were men $(n=16)$ and $46.67 \%$ women $(n=14)$, the average age of patients in the group was $57.9 \pm 1.45$ years; 108 people diagnosed with cerebral hemispheric ischemic stroke $(n=108)$, of whom $62.96 \%$ were men $(n=68)$ and $37.04 \%$ women $(n=40)$, the average age of patients in the group was $58.4 \pm$ 0.76 years. The neurocognitive assessment was performed using the international standardized scales: MMSE, MoCa were used to assess the cognitive sphere, and BDI, STAI (STAI SA, STAI TA) were used to assess psychoemotional disorders.

Results: Patients in the comprehensive treatment scheme were additionally prescribed and given two courses of rehabilitation treatment using active rehabilitation methods after the first and third examinations, recovery of cognitive and psychoemotional disorders was significantly faster and better than in group 1, where "classical" measures were applied with the predominance of medicinal therapy. Thus, the average score on the MoCa scale during examination on days 3-7 after cerebral hemispheric ischemic stroke in group 1 was $19.71 \pm 0.62$ points, in group $2-19.17 \pm 0.54$ points, and during evaluation after 6 months in group $2-24.72 \pm 0.26$ points against $22.19 \pm 0.41$ points $(p<0.0001)$ in group 1. According to the MMSE scale during examination on days 3-7 after cerebral hemispheric ischemic stroke, the average indicator in group 1 was $22.56 \pm$ 0.43 points, in group $2-22.47 \pm 0.37$ points, and when evaluated after 6 months in group $2-25.83 \pm 0.23$ points against $24.35 \pm 0.27$ points $(p=0.0001)$ in group 1 .

Conclusions: The use of methods for active rehabilitation in the treatment of patients in acute and recovery periods of cerebral hemispheric ischemic stroke significantly contributes to the acceleration and enhancement of the recuperation of cognitive and psychoemotional functions after the acute cerebral accident. The obtained results can find practical application in improving the effectiveness of therapeutic and rehabilitation programs in patients with cerebral hemispheric ischemic stroke to reduce their post-stroke deficit.
\end{abstract}

KEY WORDS: ischemic stroke, cognitive disorders, psychoemotional disorders, neurorehabilitation, functional recovery

Wiad Lek. 2021;74(8):1910-1916

\section{INTRODUCTION}

The world annually registers more than 16 million cases of stroke and more than 5 million deaths from this disease, and according to experts, about 23 million strokes and about 7.8 million deaths are expected by $2030[1,2]$.

By nature, there are two main types of stroke - the hemorrhagic and the ischemic one, which occurs by 3-5 times more often, and whose main components of the clinical presentation are motor, sensory, mental and cognitive disorders. In recent years, there has been an increase in the prevalence of post-stroke cognitive impairment $[3,4]$.

As a rule, post-stroke cognitive impairment is combined with other psycho-emotional disorders and neurological symptoms, forming a post-stroke neurocognitive deficit $[5,6,7]$.

Prospective studies show an almost 10-fold increase in the risk of developing dementia after stroke. The problem of neurocognitive deficit in patients with acute focal brain lesions is urgent worldwide, and it is a priority area of research that is constantly being studied [8].
There are a number of standardized valid scales for screening and monitoring functional status and post-stroke impairment, assessment of cognitive and anxiety-depressive disorders, in particular, the Mini-Mental State Examination (MMSE), Montreal Cognitive Assessment (MoCa), the Beck Depression Inventory (BDI), and the Spielberger-Khanin State-Trait Anxiety Inventory (STAI SA, STAI TA), which clinicians should use in their practice $[9,10]$.

Rehabilitation is one of the priority areas in the struggle against cerebral accidents. It can improve the functional recovery of patients and help reduce their disability after stroke. The contemporary European studies indicate inadequate rehabilitation care, which is often insufficient and too late, or stroke teams are often unable to fully apply all necessary treatment methods and quality systems to assess the effectiveness of rehabilitation [4].

Cognitive screening is an important part of assessing the patient's condition and treatment, whose integral part is the discharge of the patient from the stroke unit, identification and organization of further rehabilitation measures, 
which should be discussed with relatives in detail, as they play an active role in rehabilitation. According to current data, it is recommended to allocate a few hours a day for training activities in various therapeutic practices focused on a specific task. The individual rehabilitation program should include repetition and intensive use of tasks as often as possible, taking into account the individual needs and tolerance of the patient to the loads. The earliest possible start of rehabilitation measures reduces the risk of recurrent strokes and improves the functional output $[4,10,11]$.

\section{THE AIM}

The aim of the study was to evaluate the impact of active rehabilitation treatment in the scheme of comprehensive therapy of patients with cerebral hemispheric ischemic stroke on the dynamics of recovery of cognitive and psychoemotional disorders, as well as to study their correlations.

\section{MATERIALS AND METHODS}

The study involved 138 patients: 30 apparently healthy individuals (control group, CG, $\mathrm{n}=30$ ) without acute cerebrovascular disorders (anamnestic and neuroimaging), of whom $53.33 \%$ were men $(n=16)$ and $46.67 \%$ women $(\mathrm{n}=14)$, the average age of patients in the group was $57.9 \pm$ 1.45 years; 108 people diagnosed with cerebral hemispheric ischemic stroke $(\mathrm{n}=108)$, of whom $62.96 \%$ were men $(\mathrm{n}=68)$ and $37.04 \%$ women $(\mathrm{n}=40)$, the average age of patients in the group was $58.4 \pm 0.76$ years. During the study, patients with cerebral hemispheric ischemic stroke were divided into two groups: the first - group $1(n=48$, average age $-59.04 \pm 1.29$ years); the second - group 2 using methods of active rehabilitation $(n=60$, average age $-57.88 \pm 0.91$ ). In the treatment of patients of the first group, conventional "classical" measures were used with the use of medicinal therapy in accordance with the current clinical protocol of medical care for patients with ischemic stroke (Order of the Ministry of Public Health of Ukraine No.602 as of 03.08.2012), and patients of the second group were additionally prescribed and given two courses of rehabilitation treatment using the methods of active rehabilitation after the first and after the third examinations (exercises with a physical therapist 2 hours a day for 21 days). The neurocognitive assessment was performed using the international standardized scales: MMSE, MoCa were used to assess the cognitive sphere, and BDI, STAI (STAI SA, STAI TA) were used to assess psychoemotional disorders. The observation period was six months. Testing was performed on days 3-7, day 30, day 90, day 180 after cerebral hemispheric ischemic stroke.

According to the results of MMSE, 28-30 points were evaluated as the absence of cognitive impairment (CI), 2427 - precognitive impairment (preCI), 20-23 - mild cognitive impairment, 11-19 - moderate cognitive impairment. According to $\mathrm{MoCa}$ - less than 26 points were evaluated as manifestations of cognitive impairment. According to
BDI - 0-9 points were interpreted as the absence of depressive symptoms (DS), 10-15 - mild depressive symptoms (subdepression), 16-19 - moderate depressive symptoms, 20-29 - severe depressive symptoms, 30 or more points severe depression. According to STAI - 0-30 points were evaluated as low anxiety, 31-45 - moderate anxiety, 46 or more points - high anxiety. During examination on days 3-7 after cerebral hemispheric ischemic stroke, patients with an MMSE score of 10 or less and a BDI score of 30 or more were not included in the study.

The study was conducted on the basis of the Municipal Enterprise «Poltava M.V. Sklifosovskyi Regional Clinical Hospital of the Poltava Regional Council», Municipal Enterprise «The 1st City Clinical Hospital of Poltava City Council», and the Center for Neurology and Rehabilitation «Lytvynenko Clinic».

Statistical processing of the obtained data was performed using the software applications «Excel», «SPSS», «Statistica $6.0 »$, using the methods for descriptive statistics and statistical analysis. In particular, descriptive statistics are presented as mean \pm standard error of the mean $(\mathrm{M} \pm \mathrm{m})$; the Mann-Whitney U-test was used to assess intergroup differences. The nonparametric Wilcoxon test for paired quantities was used to assess the dynamic changes within groups. The correlation between quantitative indicators was assessed using Spearman's rank correlation coefficient. Pearson's $\chi^{2}$ test was used to assess the relationship between qualitative indicators. Differences were considered statistically significant at $\mathrm{p}<0.05$.

During the study, informed consent was obtained from all patients to participate in the study under the Rules of Humane Treatment of Patients in accordance with the Tokyo Declaration of the World Medical Assembly, the International Recommendations of the Helsinki Declaration of Human Rights, the Council of Europe Convention on Human Rights and Biomedicine. Law of Ukraine "Fundamentals of the legislation of Ukraine on health care" as amended, Orders of the Ministry of Public Health of Ukraine, the Code of Ethics of Physicians of Ukraine and the Code of Ethics of Scientists of Ukraine, as well as current legislation.

\section{RESULTS}

Analyzing the structure by the degree of cognitive impairment in patients of group 1 and group 2 by MMSE, it was found that on days 3-7 after cerebral hemispheric ischemic stroke in group 1, 4.2\% (2/48) of patients had no manifestations of cognitive impairment, 29.1\% (14/48) had precognitive disorders, $54.2 \%$ (26/48) - mild cognitive impairments, $12.5 \%$ (6/48) - manifestations of moderate cognitive impairment, in group 2 , in this period all patients had cognitive dysfunction: $31.7 \%(19 / 60)$ had precognitive disorders, 58.3\% (35/60) - mild disorders, 10\% (6/60) manifestations of cognitive disorders corresponding to a moderate degree. During examination six months later in group 1, MMSE scores corresponding to the absence of cognitive impairment were $4.2 \%(2 / 48), 60.4 \%(29 / 48)$ had 
precognitive impairments, $33.3 \%$ (16/48) - mild cognitive impairment, $2.1 \%(1 / 48)$ - manifestations of moderate cognitive impairment, whereas in group 2, 16.7\% (10/60) had no manifestations of cognitive impairment, $71.7 \%$ (43/60) had precognitive impairment, $11.6 \%$ (7/60) - mild cognitive impairment, and patients with moderate cognitive impairment in group 2 at this time were absent. The distribution of patients according to the degree of cognitive impairment on the MMSE scale at the beginning of treatment and 6 months after cerebral hemispheric ischemic stroke is shown in Fig. 1.

Analyzing the structure according to the degrees of depressive symptoms in patients of group 1 and group 2 by BDI, it was found that on days 3-7 after cerebral hemispheric ischemic stroke in group $1,20.8 \%(10 / 48)$ of patients had no depressive symptoms, 39.6\% (19/48) had mild depressive symptoms, 37.5\% (18/48) - moderate depressive symptoms, $2.1 \%(1 / 48)$ - severe depressive symptoms, whereas in group 2 , the absence of depressive symptoms was found in 10\% (6/60) of patients, 35\% (21/60) had mild depressive symptoms, 55\% (33/60) had moderate depressive symptoms. During examination six months after cerebral hemispheric ischemic stroke in group 1, 47.9\% (23/48) had mild depressive symptoms, 52.1\% (25/48) had moderate depressive symptoms, whereas in group 2, 20\% $(12 / 60)$ did not have depressive symptoms, $73.3 \%(44 / 60)$ had mild depressive symptoms, 6.7\% (4/60) had moderate depressive symptoms. The distribution of patients according to the severity of depressive symptoms on the BDI scale at the beginning of treatment and 6 months after cerebral hemispheric ischemic stroke is shown in Fig. 2.

Analyzing the structure of the severity of reactive (situational) anxiety in patients of group 1 and group 2 according to STAI (SA), it was found that on days 3-7 after cerebral hemispheric ischemic stroke in group 1, 45.8\% (22/48) of patients had low anxiety, the same percentage $(22 / 48)$ had moderate reactive anxiety, $8.4 \%(4 / 48)$ - high anxiety, in group 2 at this time 30\% (18/60) had low anxiety, 56.7\% $(34 / 60)$ - moderate, $13.3 \%$ (8/60) - high reactive anxiety. When examined six months after cerebral hemispheric ischemic stroke in group 1, 33.3\% (16/48) had low anxiety, $50 \%(24 / 48)$ - moderate, $16.7 \%(8 / 48)$ - high anxiety, whereas in group 2 at this time the level of high reactive anxiety was not observed, $25 \%(15 / 60)$ had moderate anxiety, $75 \%(45 / 60)$ - low anxiety. The distribution of patients by the degree of reactive (situational) anxiety according to STAI (SA) at the beginning of treatment and 6 months after cerebral hemispheric ischemic stroke is shown in Fig. 3a.

Analyzing the structure of the severity of personal anxiety in patients of group 1 and group 2 according to STAI (TA), it was found that on days 3-7 after cerebral hemispheric ischemic stroke in group $154.2 \%(26 / 48)$

Table I. Correlation between indicators of cognitive and psychoemotional disorders in different observation periods after cerebral hemispheric ischemic stroke in groups 1 and 2

\begin{tabular}{|c|c|c|c|c|}
\hline \multirow{2}{*}{ Group } & \multirow{2}{*}{ Indicators } & \multicolumn{3}{|c|}{ Correlation coefficient, $R$} \\
\hline & & 1 mths. & 3 mths. & 6 mths. \\
\hline \multirow{10}{*}{ 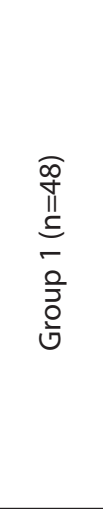 } & MoCa - MMSE & $+0.768^{* *}$ & $+0.427^{* *}$ & $+0.514^{* *}$ \\
\hline & $\mathrm{MoCa}-\mathrm{BDI}$ & -0.016 & -0.256 & +0.193 \\
\hline & MoCa - STAI SA & 0.074 & 0.127 & +0.453 \\
\hline & MoCa - STAITA & -0.067 & -0.052 & $+0.367^{*}$ \\
\hline & MMSE - BDI & +0.133 & +0.016 & $+0.287^{*}$ \\
\hline & MMSE - STAI SA & +0.187 & $+0.372^{* *}$ & $+0.359^{*}$ \\
\hline & MMSE - STAI TA & +0.038 & +0.152 & $+0.292^{*}$ \\
\hline & BDI - STAI SA & +0.063 & -0.072 & $+0.442^{* *}$ \\
\hline & BDI - STAITA & -0.051 & -0.071 & +0.228 \\
\hline & STAI SA - STAITA & $+0.381^{* *}$ & $+0.494^{* *}$ & $+0.45^{* *}$ \\
\hline \multirow{10}{*}{ 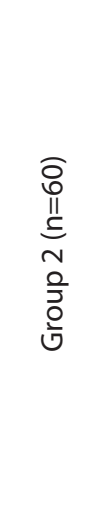 } & MoCa - MMSE & $+0.79 * *$ & $+0.619^{* *}$ & $+0.73^{* *}$ \\
\hline & MoCa - BDI & $+0.325^{*}$ & $+0.353^{* *}$ & $+0.421^{* *}$ \\
\hline & MoCa - STAI SA & $+0.352^{* *}$ & +0.203 & $+0.426^{* *}$ \\
\hline & MoCa - STAITA & $+0.348^{* *}$ & $+0.267^{*}$ & $+0.401^{* *}$ \\
\hline & MMSE - BDI & $+0.269 *$ & +0.111 & +0.212 \\
\hline & MMSE - STAI SA & $+0.309 *$ & -0.007 & +0.185 \\
\hline & MMSE - STAI TA & $+0.362^{* *}$ & +0.025 & +0.158 \\
\hline & BDI - STAI SA & $+0.441^{* *}$ & $+0.317^{*}$ & $+0.511^{* *}$ \\
\hline & BDI - STAITA & $+0.416^{* *}$ & $+0.682^{* *}$ & $+0.657^{* *}$ \\
\hline & STAI SA - STAI TA & $+0.891^{* *}$ & $+0.519^{* *}$ & $+0.551^{* *}$ \\
\hline
\end{tabular}

Note: ${ }^{*}$ - the correlation is significant at the level of $p<0.05,{ }^{* *}$ - the correlation is significant at the level of $p<0.01$. 


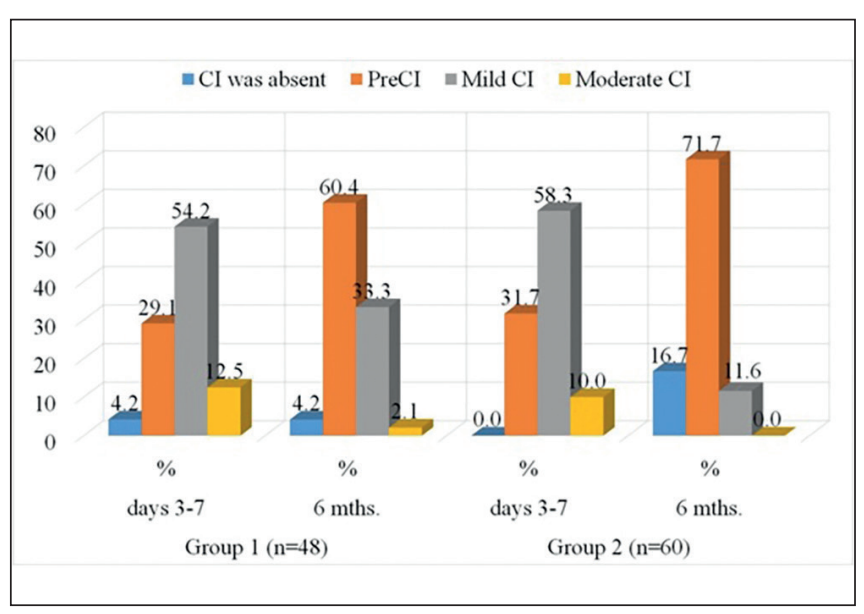

Fig. 1. MMSE: The distribution of patients by the degree of cognitive impairment at the beginning of treatment and six months after cerebral hemispheric ischemic stroke, \%

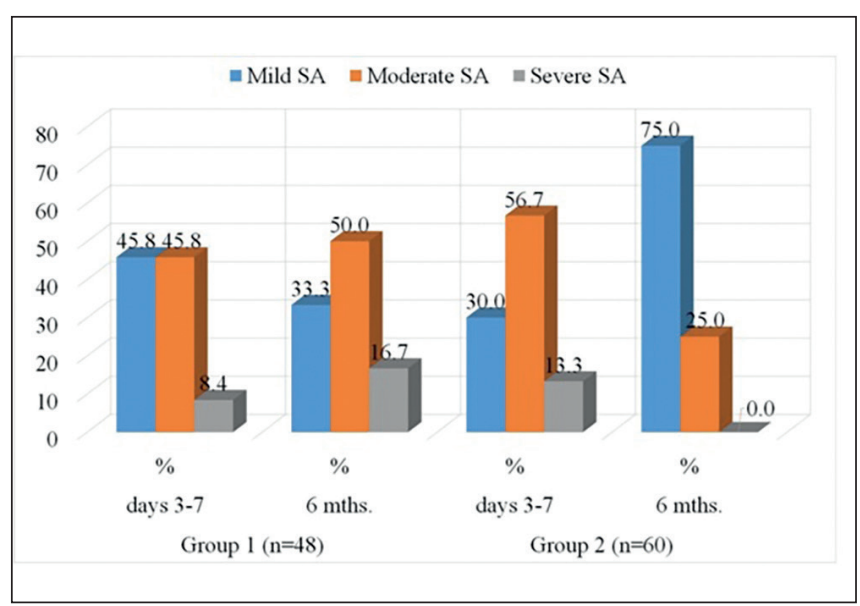

Fig. 3a. STAI (SA): The distribution of patients by the degree of reactive anxiety at the beginning of treatment and six months after cerebral hemispheric ischemic stroke, \%

of patients had low anxiety, 35.4\% (17 / 48) - moderate personal anxiety, $10.4 \%(5 / 48)$ - high anxiety, in group 2 at this time $41.7 \%(25 / 60)$ had low anxiety, $35 \%(21 / 60)-$ moderate, $23.3 \%(14 / 60)$ - high personal anxiety. During examination six months after cerebral hemispheric ischemic stroke in group $1,47.9 \%(23 / 48)$ had low anxiety, $29.2 \%(14 / 48)$ - moderate, $22.9 \%$ (11/48) - high anxiety, whereas in group 2 at this time, only $3.3 \%(2 / 60)$ of people had high personal anxiety, $26.7 \%(16 / 60)$ - moderate, and $70 \%(42 / 60)-$ low anxiety. The distribution of patients by the degree of personal anxiety according to STAI (TA) at the beginning of treatment and 6 months after cerebral hemispheric ischemic stroke is shown in Fig. $3 \mathrm{~b}$.

When comparing groups by age and sex, no statistically significant differences were found.

When comparing the indicators of neurocognitive status by MMSE, MoCa, BDI, STAI (SA, TA) on days 3-7 after cerebral hemispheric stroke between the control group and the study groups 1 and 2 on all scales, we revealed statistically significant intergroup differences $\left(\mathrm{p}_{0-1}, \mathrm{p}_{0-2}\right.$,

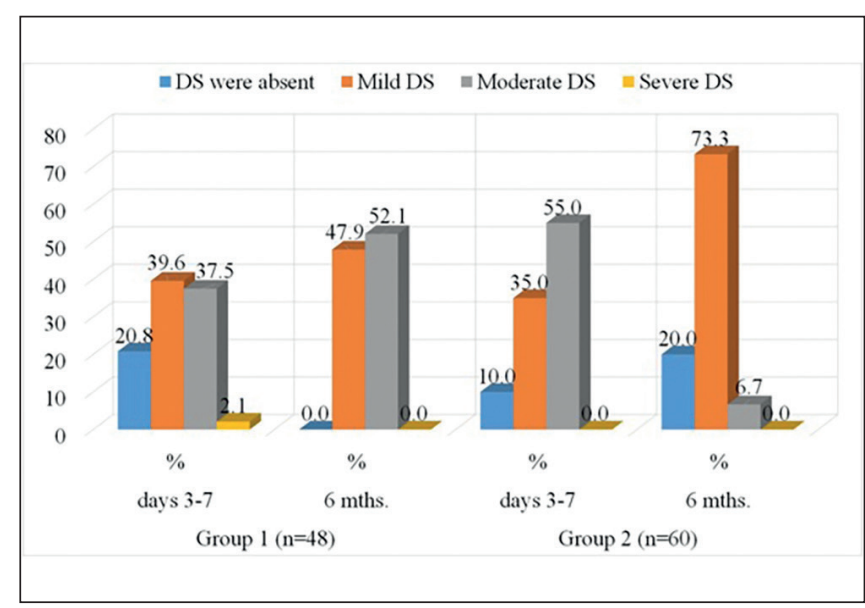

Fig. 2. BDI: The distribution of patients according to the degree of depressive symptoms at the beginning of treatment and six months after cerebral hemispheric ischemic stroke, \%

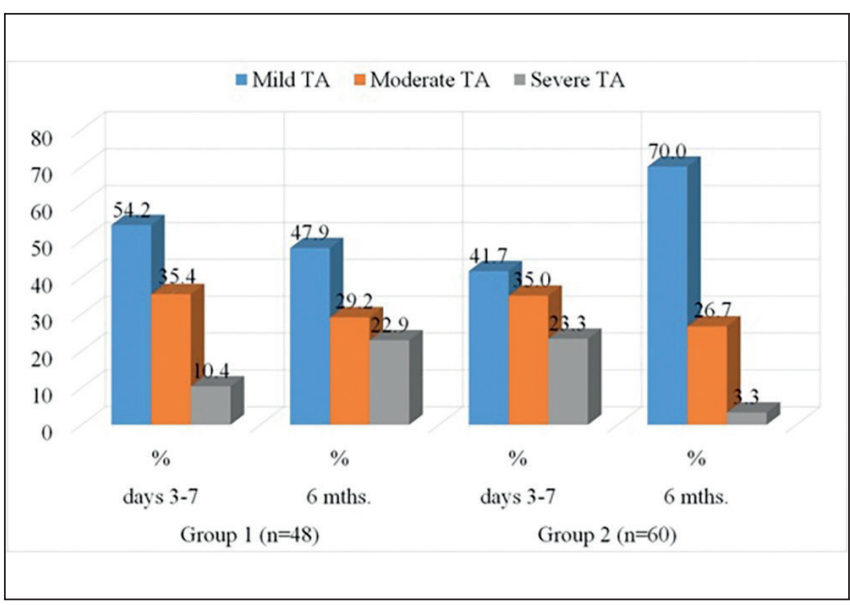

Fig. 3b. STAI (TA): The distribution of patients by the degree of personal anxiety at the beginning of treatment and six months after cerebral hemispheric ischemic stroke, $\%$

respectively), whereas there was no statistically significant difference $\left(\mathrm{p}_{1-2}\right)$ between groups 1 and 2 on all scales at this time.

- MMSE - $28.3(95 \% \mathrm{CI}=27.96-28.64)$ points in the control group against $22.56(95 \% \mathrm{CI}=21.72-23.41)$ points in group $1\left(\mathrm{p}_{0-1}<0.0001\right)$ and $22.47(95 \% \mathrm{CI}=21.75-23.18)$ points in group $2\left(\mathrm{p}_{0-2}<0.0001 ; \mathrm{p}_{1-2}=0.92\right.$ respectively);

- MoCa - 27.57 (95\% CI =27.19 - 27.94) points in the control group against $19.71(95 \% \mathrm{CI}=18.49-20.92)$ points in group $1\left(\mathrm{p}_{0-1}<0.0001\right)$ and $19.17(95 \% \mathrm{CI}=18.1-20.23)$ points in group $2\left(\mathrm{p}_{0-2}<0.0001 ; \mathrm{p}_{1-2}=0.47\right.$, respectively);

- BDI - $7.7(95 \% \mathrm{CI}=6.7-8.7)$ points in the control group against $13.21(95 \% \mathrm{CI}=12.06-14.35)$ points in group $1\left(\mathrm{p}_{0-1}<0.0001\right)$ and $14.42(95 \% \mathrm{CI}=13.5-15.34)$ points in group $2\left(\mathrm{p}_{0-2}<0.0001 ; \mathrm{p}_{1-2}=0.14\right.$, respectively);

- STAI SA - $28.07(95 \% \mathrm{CI}=27.05-29.09)$ points in the control group against $33.35(95 \% \mathrm{CI}=31.28-35.43)$ points in group $1\left(\mathrm{p}_{0-1}=0.001\right)$ and $35.45(95 \% \mathrm{CI}=33.52-37.38)$ points in group $2\left(\mathrm{p}_{0-2}<0.0001 ; \mathrm{p}_{1-2}=0.12\right.$ respectively);

- STAI TA - $29.17(95 \% \mathrm{CI}=28.29-30.04)$ points in the 


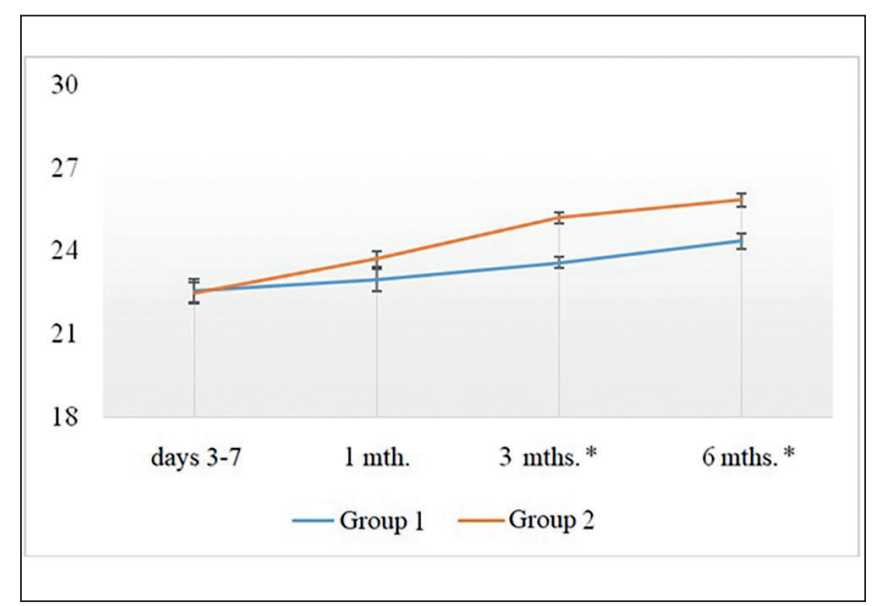

Fig. 4a. Mean values (with error bars) of scores on the MMSE scale in the dynamics of patients in the study groups.

Note * - proven difference between the group indicators $(p<0.05)$

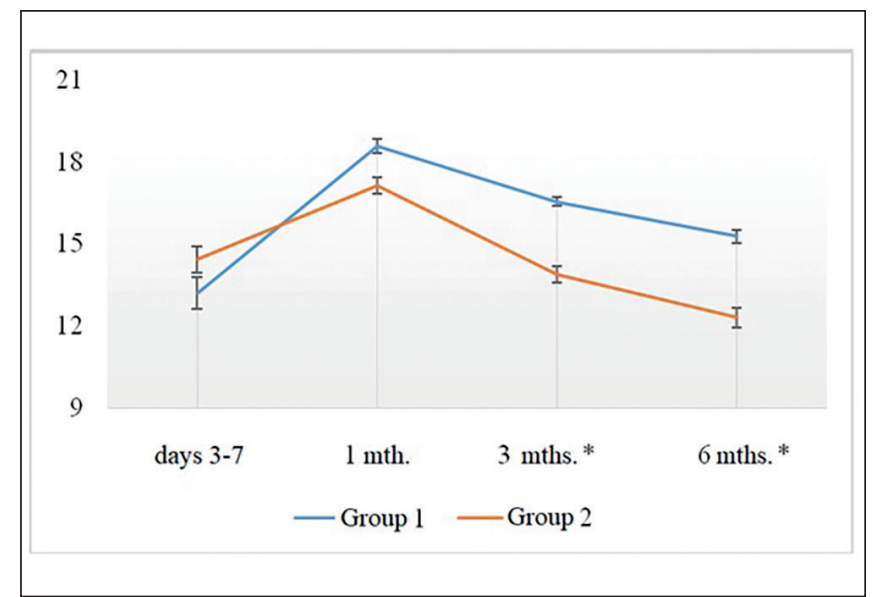

Fig. 4c. Mean values (with error bars) of points on the BDI scale in the dynamics of patients in the study groups.

Note $*$ - the proven difference between the group indicators $(p<0.05)$

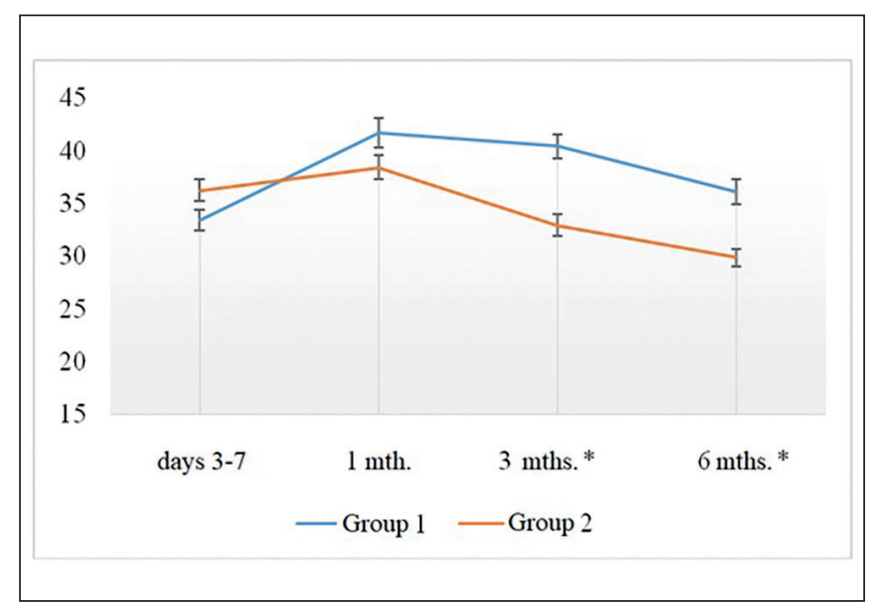

Fig. 4e. Mean values (with error bars) on the STAITA scale in the dynamics of patients in the study groups.

Note ${ }^{*}$ - the proven difference between the group indicators $(p<0.05)$

control group against $33.42(95 \% \mathrm{CI}=31.53-35.31)$ points in group $1\left(\mathrm{p}_{0-1}=0,0015\right)$ and $36.22(95 \% \mathrm{CI}=34.14-38.29)$ points in group $2\left(\mathrm{p}_{0-2}<0.0001 ; \mathrm{p}_{1-2}=0.055\right.$, respectively $)$.

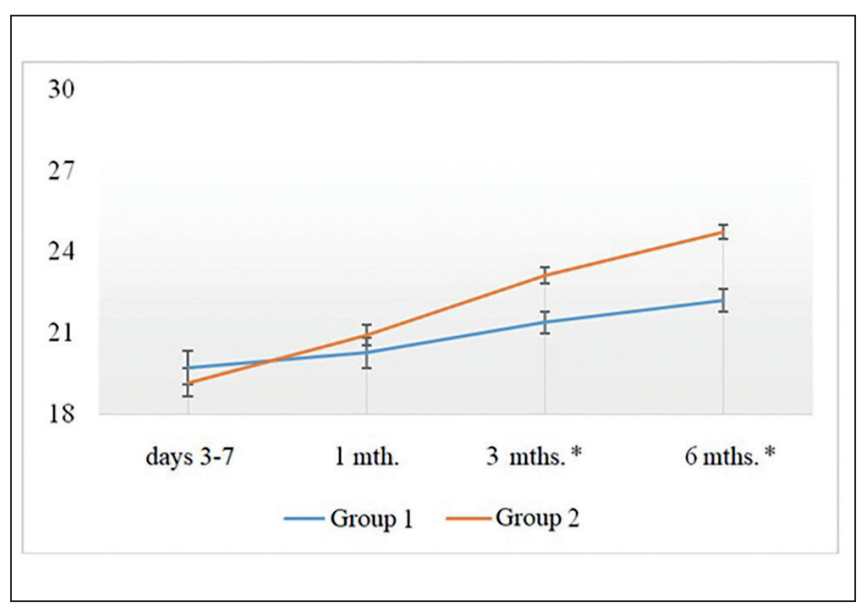

Fig. 4b. Mean values (with error bars) of points on the MoCa scale in the dynamics of patients in the study groups.

Note * - the proven difference between the group indicators $(p<0.05)$

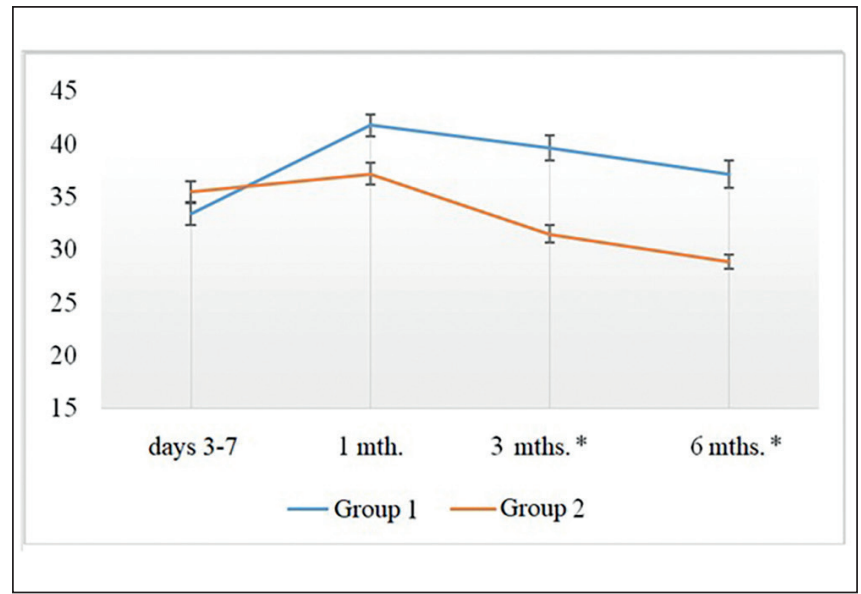

Fig. 4d. Mean values (with error bars) on the STAI SA scale in the dynamics of patients in the study groups.

Note * - the proven difference between the group indicators $(p<0.05)$

During examination on the 30th day after cerebral hemispheric ischemic stroke on the scores of the scales of the cognitive sphere, no significant difference was found, and the indicators of psycho-emotional disorders differed statistically significantly between the study groups by BDI and STAI SA: MMSE - 22.94 $(95 \% \mathrm{CI}=22.15-23,73)$ points against 23.7 $(95 \% \mathrm{CI}=23.18-24.22)$ points, respectively $(\mathrm{p}=0.122) ; \mathrm{MoCa}$ $-20.27(95 \% \mathrm{CI}=19.17-21.37)$ points against $20.92(95 \% \mathrm{CI}=$ $20.19-21.64)$ points, respectively $(\mathrm{p}=0.47)$; $\mathrm{BDI}-18.56(95 \%$ $\mathrm{CI}=18.08-19.04)$ points against $17.12(95 \% \mathrm{CI}=16.51-17.72)$ points respectively $(\mathrm{p}=0.002)$; STAISA $-41.75(95 \% \mathrm{CI}=39.67$ - 43.83) points against $37.17(95 \% \mathrm{CI}=35.16-39.17)$ points, respectively $(\mathrm{p}=0.02)$; STAI TA $-41.67(95 \% \mathrm{CI}=38.88-$ 44.45) points against $38.42(95 \% \mathrm{CI}=36.19-40.64)$ points, respectively $(\mathrm{p}=0.148)$.

During evaluation on the 90th day in group 1, there was a worse recovery of neurocognitive functions as compared to group 2, where there was a statistically significant positive dynamics on all scales: MMSE - 23.56 (95\% CI = $23.17-23.95)$ points against $25.2(95 \% \mathrm{CI}=24.82-25.58)$ points, respectively $(\mathrm{p}<0.0001)$; $\mathrm{MoCa}-21.38(95 \% \mathrm{CI}=$ $20.59-22.16)$ points against $23.1(95 \% \mathrm{CI}=22.52-23.68)$ 
points, respectively $(\mathrm{p}=0.0012)$; $\mathrm{BDI}-16.54(95 \% \mathrm{CI}=$ $16.21-16.88)$ points against $13.88(95 \% \mathrm{CI}=13.29-14.48)$ points, respectively $(\mathrm{p}<0.0001)$; STAI SA - $39.65(95 \%$ $\mathrm{CI}=37.34-41.95)$ points against $31.47(95 \% \mathrm{CI}=29.81-$ $33.12)$ points, respectively $(\mathrm{p}<0.0001)$; STAI TA -40.4 $(95 \% \mathrm{CI}=37.64-43.15)$ points against $32.92(95 \% \mathrm{CI}=$ $30.94-34.9)$ points, respectively $(\mathrm{p}<0.0001)$.

A similar situation to the previous assessment was observed in testing six months after acute cerebral accident, which indicates a significantly better recovery of impaired cognitive and psychoemotional functions after cerebral hemispheric ischemic stroke under the influence of active rehabilitation methods. Thus, when evaluating patients on the studied scales on the 180th day, the following values were obtained in group 1 against group 2: $\mathrm{MMSE}-24.35(95 \% \mathrm{CI}=23.83-24.88)$ points against $25.83(95 \% \mathrm{CI})=25.38-26.29)$ points, respectively $(\mathrm{p}=0.00013) ; \mathrm{MoCa}-22.19(95 \% \mathrm{CI}=21.38-23.0)$ points against $24.72(95 \% \mathrm{CI}=24.21-25.23)$ points, respectively $(\mathrm{p}<0.0001)$; BDI $-15.27(95 \% \mathrm{CI}=14.78-15.77)$ points against $12.3(95 \% \mathrm{CI}=11.57-13.03)$ points, respectively $(\mathrm{p}<0.0001)$; STAI SA - 37.13 $(95 \% \mathrm{CI}=34.57-39.68)$ points against 28.88 $(95 \% \mathrm{CI}=27.59-30.18)$ points respectively $(\mathrm{p}=0.0001)$; STAI $\mathrm{TA}-36.08(95 \% \mathrm{CI}=33.76-38.41)$ points against $29.83(95 \%$ $\mathrm{CI}=28.3-31.36)$ points, respectively $(\mathrm{p}<0.0001)$.

The dynamics of recovery of cognitive and psychoemotional disorders in patients of the studied groups is shown in Fig. 4a-4e.

In order to clarify the changes in the cognitive and psychoemotional sphere in patients with cerebral hemispheric ischemic stroke, a correlation analysis was additionally conducted between the relevant diagnostic parameters in all groups at different observation periods.

It was found that in the control group $(\mathrm{n}=30)$, there are statistically significant correlations between the following indicators: STAI SA and STAI TA $(\mathrm{R}=0.461, \mathrm{p}=0.0103)$, STAI SA and BDI $(\mathrm{R}=0.462, \mathrm{p}=0,0102)$, STAI TA and BDI $(\mathrm{R}=0.533, \mathrm{p}=0.0024)$.

In the group of patients with cerebral hemispheric ischemic stroke $(\mathrm{n}=108)$ during examination on days 3-7 after acute cerebral catastrophe, we revealed statistically significant positive correlations between MMSE and $\mathrm{MoCa}(\mathrm{R}=0.814, \mathrm{p}<0.0001)$, BDI and MMSE $(\mathrm{R}=0.461$, $\mathrm{p}<0.0001)$, BDI and $\mathrm{MoCa}(\mathrm{R}=0.362, \mathrm{p}=0.0001)$, STAI SA and MMSE $(\mathrm{R}=0.369, \mathrm{p}<0.0001)$, STAI SA and BDI $(\mathrm{R}=0.339, \mathrm{p}=0.0003)$, STAI TA and MMSE $(\mathrm{R}=0.216$, $\mathrm{p}=0.0248)$, STAI TA and BDI $(\mathrm{R}=0.365, \mathrm{p}=0.0001)$, STAI SA and STAI TA $(\mathrm{R}=0.713, \mathrm{p}<0.0001)$.

Correlation relationships in the study groups between indicators of cognitive and psychoemotional disorders are presented in Table I.

\section{DISCUSSION}

Due to the activation of neuroplasticity and neuroreparation, the most functional changes can be expected during the first few weeks and / or months, therefore, intensive rehabilitation with active physical techniques during this period has the greatest impact, whereas greater intensity and duration of exercise in a favorable stimulating environment for recovery contribute to a positive effect on the functional recovery of patients $[11,12]$. The analysis of the obtained results shows that in group 2, whose patients in the comprehensive treatment scheme were additionally prescribed and given two courses of rehabilitation treatment using active rehabilitation methods after the first and third examinations, recovery of cognitive and psychoemotional disorders was significantly faster and better than in group 1, where "classical" measures were applied with the predominance of medicinal therapy $[13,14,15]$. Thus, the average score on the MoCa scale during examination on days 3-7 after cerebral hemispheric ischemic stroke in group 1 was $19.71 \pm 0.62$ points, in group $2-19.17 \pm 0.54$ points, and during evaluation after 6 months in group $2-24.72 \pm 0.26$ points against $22.19 \pm 0.41$ points ( $\mathrm{p}<0.0001$ ) in group 1. According to the MMSE scale during examination on days 3-7 after cerebral hemispheric ischemic stroke, the average indicator in group 1 was $22.56 \pm 0.43$ points, in group $2-22.47 \pm 0.37$ points, and when evaluated after 6 months in group $2-25.83 \pm 0.23$ points against $24.35 \pm 0.27$ points $(\mathrm{p}=0.0001)$ in group 1 . The average score on the BDI scale during examination on days 3-7 after cerebral hemispheric ischemic stroke in group 1 was $13.21 \pm$ 0.58 points, in group $2-14.42 \pm 0.47$ points, and during evaluation after 6 months in group 2, it decreased to $12.3 \pm$ 0.37 points against $15.27 \pm 0.25$ points $(\mathrm{p}<0.0001)$ in group 1. On the STAI SA scale, during examination on days 3-7 after cerebral hemispheric ischemic stroke, the average indicator in group 1 was $33.35 \pm 1.06$ points, in group $2-35.45 \pm 0.98$ points, and during evaluation after 6 months in group $2-28.88 \pm 0.66$ points against $37.13 \pm$ 1.31 points $(\mathrm{p}=0.0001)$ in group 1 . According to the STAI TA scale during examination on days 3-7 after cerebral hemispheric ischemic stroke, the average indicator in group 1 was $33.42 \pm 0.96$ points, in group $2-36.22 \pm 1.06$ points, and during evaluation after 6 months in group 2, it decreased to $29.83 \pm 0.78$ points against $36.08 \pm 1.19$ points in group 1 $(\mathrm{p}<0.0001)$.

\section{CONCLUSIONS}

The use of methods for active rehabilitation in the treatment of patients in acute and recovery periods of cerebral hemispheric ischemic stroke significantly contributes to the acceleration and enhancement of the recuperation of cognitive and psychoemotional functions after the acute cerebral accident. The obtained results can find practical application in improving the effectiveness of therapeutic and rehabilitation programs in patients with cerebral hemispheric ischemic stroke to reduce their post-stroke deficit.

\section{REFERENCES}

1. Katan M., Luft A. Global burden of stroke. Seminars in Neurology. 2018; 38(02):208-211. doi 10.1055/s-0038-1649503.

2. Virani S.S., Alonso A., Benjamin E.J. et al. Heart Disease and Stroke Statistics-2020 Update: A Report From the American Heart Association. Circulation. 2020; 141(9):e139-e596. doi: 10.1161/ CIR.0000000000000757. 
3. Dichgans M., Leys D. Vascular Cognitive Impairment. Circulation Research. 2017; 120:573-591. doi: 10.1161/CIRCRESAHA.116.308426.

4. Norrving B., Barrick J., Davalos A. et al. Action Plan for Stroke in Europe 2018-2030. European Stroke Journal. 2018; 3(4):309-336. doi: $10.1177 / 2396987318808719$.

5. Pushko 0.0., Lytvynenko N.V. Peculiarities of neurocognitive status of patients in the acute ischemic stroke phase of different hemispheric localization. World of Medicine and Biology. 2020; 2(72):99-103. doi: 10.26724/2079-8334-2020-2-72-99-103.

6. Chun H.Y.Y., Whiteley W.N., Dennis M.S. et al. Anxiety after stroke the importance of subtyping. Stroke. 2018;49(3):556-564. doi: 10.1161/ STROKEAHA.117.020078.

7. Graff-Radford J. Vascular cognitive impairment. Continuum: Lifelong Learning in Neurology. 2019; 25(1):147-164. doi: 10.1212/ CON.0000000000000684.

8. Benjamin E.J., Muntner P., Alonso A. et al. Heart Disease and Stroke Statistics-2019 Update: A Report From the American Heart Association. Circulation. 2019; 139(10):e56-e528. doi: 10.1161/ CIR.0000000000000659.

9. Ministerstvo okhorony zdorovia Ukrainy. Unifikovanyi klinichnyi protokol medychnoidopomohy «lshemichnyi insult (ekstrena, pervynna, vtorynna (spetsializovana) medychnadopomoha, medychnareabilitatsiia). 2012. Nakaz №602. 2012 serpen 03. Available from: https://dec.gov.ua/wpcontent/uploads/images/dodatki/2012_602/2012_602dod4ykpmd. pdf. (Ukrainian)

10. European Physical and Rehabilitation Medicine Bodies Alliance. White Book on Physical and Rehabilitation Medicine in Europe. European Journal of Physical and Rehabilitation Medicine. 2018; 54(2):125321. doi 10.23736/S1973-9087.18.05143-2.

11. Lanctot K.L., Lindsay M.P., Smith E.E. et al. Canadian Stroke Best Practice Recommendations: Mood, Cognition and Fatigue following Stroke, 6th edition update 2019. International Journal of Stroke. 2020; 15(6):668-688. doi: 10.1177/1747493019847334.

12. Zhang M., Wang Q., Jiang Y. et al. Optimization of Early Mobilization Program for Patients With Acute Ischemic Stroke: An Orthogonal Design. Frontiers in Neurology. 2021; 12:645811. doi: 10.3389/ fneur.2021.645811.

13. Tararoshchenko M.V., Babkina N.V., Aliinyk D.0. et al. Rannia reabilitatsiia khvorykh $z$ insultom v umovakh nevrolohichnoho viddilennia. Ukrainskyi nevrolohichnyi zhurnal. 2015; 2:77-81. (Ukrainian)
14. Billinger S.A., Arena R., Bernhardt J. et al. Physical Activity and Exercise Recommendations for Stroke Survivors: a Statement for Healthcare Professionals From the American Heart Association/American Stroke Association. Stroke. 2014; 45:2532-2553. doi: 10.1161/ STR.0000000000000022.

15. Whitehead S., Baalbergen E. Post-stroke rehabilitation. South African Medical Journal. 2019; 2(109):81-83. doi: 10.7196/SAMJ.2019. v109i2.00011.

The study is a part of the research project "The influence of comprehensive physical (medical) rehabilitation on motor, cognitive and psychoemotional disorders in acute cerebrovascular pathology: optimization of diagnosis, prognosis and treatment with the substantiation of a differentiated approach", state registration No. 0120 U105395.

\section{ORCID and contributionship:}

Oleksandr O. Pushko: 0000-0001-7309-4798 A-F

\section{Conflict of interest:}

The Author declare no conflict of interest.

\section{CORRESPONDING AUTHOR Oleksandr 0. Pushko \\ Poltava State Medical University \\ 23 Shevchenko St., 36011 Poltava, Ukraine \\ tel: +380664221368 \\ e-mail: olexandrpushko@gmail.com}

Received: 14.04 .2021

Accepted: 30.07 .2021

A - Work concept and design, B - Data collection and analysis, C - Responsibility for statistical analysis, $\mathbf{D}$-Writing the article, $\mathbf{E}$-Critical review, $\mathbf{F}$ - Final approval of the article 